\title{
HISPANIC AMERICANS AND THE MILITARY: MEASURING MICROAGGRESSION AND ITS MEDIATING EFFECTS ON ORGANIZATIONAL CLIMATE FACTORS
}

Ulysses J. Brown, III, Savannah State University, U.S.A. Chevanese Samms Brown, Savannah State University, U.S.A.

$$
\text { dx.doi.org/10.18374/IJBR-20-1.7 }
$$

\begin{abstract}
This study was designed to examine the role of microaggression and how it may impact the performance of Hispanic Americans serving in the United States of America Armed Forces. Responses of 1,056 Hispanic Americans who were serving in active duty military units were evaluated using structural equation modeling. Findings indicated that organizational climate factors predict microaggression, leadership cohesion, workgroup cohesion, and workgroup effectiveness. Limitations, contributions, future research, and recommendations are discussed. Any opinions expressed in this study are those of the authors and should not be construed to represent the official position of DEOMI, the military services, or the Department of Defense.
\end{abstract}

Keywords: Military, United States Armed Forces, MicroagGression, MicroagGressions, Diversity. 